\title{
P0140
}

\section{EFFECTS OF LIGHTING ON PERCEPTION OF SPACIOUSNESS}

\author{
Hiroyuki MIYAKE et al.
}

DOI 10.25039/x46.2019.PO140

from

CIE x046:2019

\section{Proceedings}

of the

29th CIE SESSION

Washington D.C., USA, June 14 - 22, 2019

(DOI 10.25039/x46.2019)

The paper has been presented at the 29th CIE Session, Washington D.C., USA, June 14-22, 2019. It has not been peer-reviewed by CIE.

\section{(C) CIE 2019}

All rights reserved. Unless otherwise specified, no part of this publication may be reproduced or utilized in any form or by any means, electronic or mechanical, including photocopying and microfilm, without permission in writing from CIE Central Bureau at the address below. Any mention of organizations or products does not imply endorsement by the CIE.

This paper is made available open access for individual use. However, in all other cases all rights are reserved unless explicit permission is sought from and given by the CIE.

CIE Central Bureau

Babenbergerstrasse 9

A-1010 Vienna

Austria

Tel.: +43 17143187

e-mail: ciecb@cie.co.at

www.cie.co.at 


\title{
EFFECTS OF LIGHTING ON PERCEPTION OF SPACIOUSNESS
}

\author{
Miyake, H. ${ }^{1}$, Yamamoto, $\mathrm{T}^{2}$, Yamaguchi, $\mathrm{H}^{3}$, Yoshizawa, N. ${ }^{4}$ \\ ${ }^{1}$ Tokyo University of Science, Chiba, JAPAN / Arup, Tokyo, JAPAN, \\ ${ }^{2}$ Tokyo University of Science, Chiba, JAPAN, ${ }^{3}$ National Institute for Land and Infrastructure \\ Management, Tsukuba, JAPAN, ${ }^{4}$ Tokyo University of Science, Chiba, JAPAN \\ hiroyuki.miyake@arup.com
}

DOI 10.25039/x46.2019.PO140

\begin{abstract}
With different lighting, one's perception of spaciousness could be different even in the same room. From experience, the more a room is lit, the more the spaciousness seems to be. The localisation of light also seems to have an effect. This research is to examine if these hypotheses are true, and to propose a model to quantify the effect of light to spaciousness, using luminance and their three-dimensional localization. We had an experiment in a living room with different lightings, asking subjects about their perception of spaciousness compared to the reference lighting scene. It is proved that both quantity and localisation of light influence spaciousness. Luminance level is measured using HDR image processing, and the coordinate value of each pixel is measured using Radiance RTRACE command with a virtually rebuilt room.
\end{abstract}

Keywords: Spaciousness, brightness, perception of volume, luminance, three-dimensional localisation of light, Radiance, simulation, 3D luminance mapping

\section{Research theme}

\subsection{Purpose and status of the study}

Spaciousness and brightness are important values of space. There are suitable range of values of spaciousness and brightness for different rooms according to the purpose of room, users and other conditions. Spaciousness is primarily based on volume and dimensions (Uchida, 1979; Imamoglu, 1986; Komiyama and Hatsumi, 1996) but could also be affected by lighting environment, colour of surfaces and other factors (Inui et al, 1972a; Inui et al, 1972b; Inui et al, 1972c; Christoph, 2018a; Christoph, 2018b). As physical volume is usually not infinite because of available space which is restricted by cost, technology, law, maintenance plan, etc. Thus, it is useful to add up spaciousness using lighting. For example, the quantity of light, contrast, localization in the room. (Figure 1)

To evaluate the effect of lighting to spaciousness, it is necessary to develop a method to measure luminance comprehensively and its three-dimensional location in the same time. We named this method to add information to luminance data as "three-dimensional luminance mapping". In virtual space, we have developed a script using RTRACE command in Radiance to capture luminance and location (distance and unit vector $x, y, z$ value from view point to object surface). With this command, it's also possible to add different data, like the type of the object (wall, ceiling, floor, furniture), colour, specularity etc. which could be used for further research (Figure 2). In real space, we have a method using L-CEPT to capture luminance image using equisolid angle fisheye lens, but we are still on the way to developing a system to measure the distance and the location information of each pixel.

The brightness is also a subject of this research. There are research methods to quantify brightness using luminance, and some of them uses contrast and localization as variants. However, location information used in those researches is only two-dimensional, that is, the placement on the luminance image is considered but not the depth. (Waldram, 1969; Tiller, 1995; Cuttle, 2004; Kato and Sekiguchi, 2005; Kobayashi et al., 2008; Boyce, 2014; Aya et al., 2015; Duff, 2015; Sullivan, 2018) Brightness could also be affected by distance and threedimensional luminance mapping will make it possible to evaluate the brightness more efficiently and precisely. 


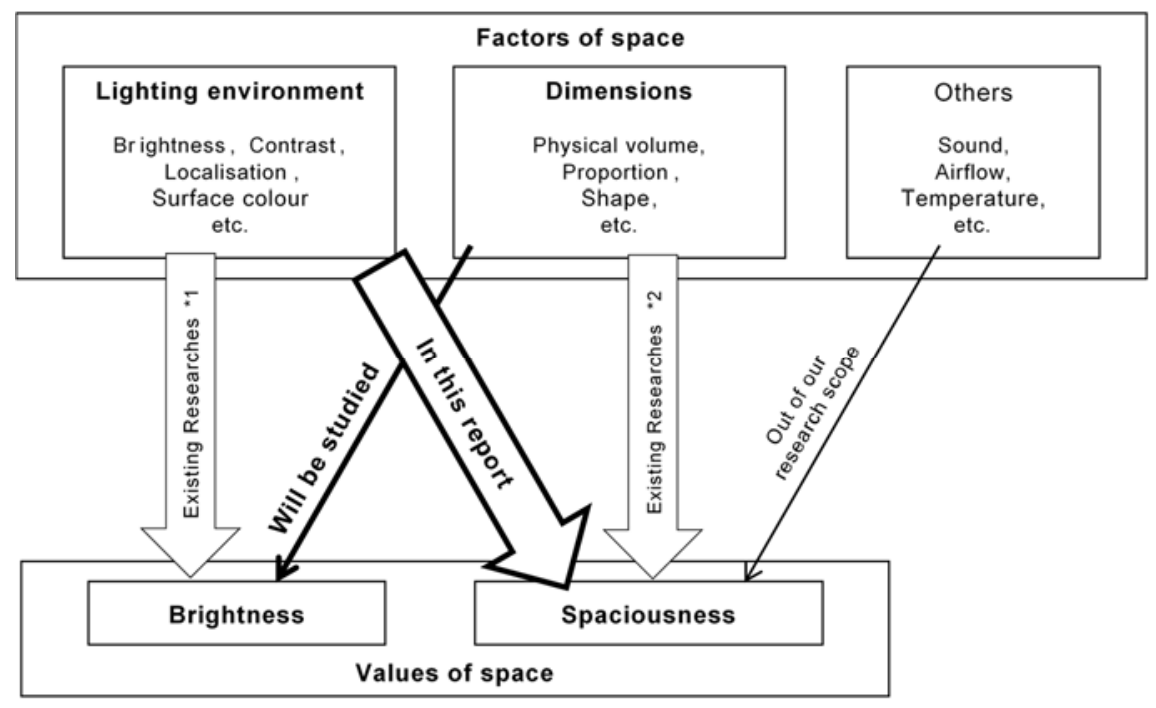

Figure 1 - Factors and Values in this Research
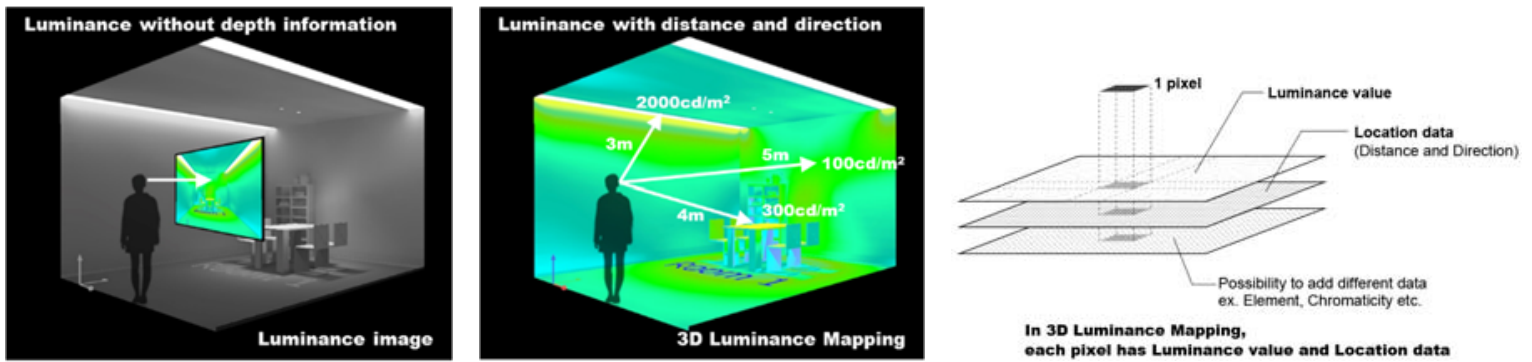

Figure 2 - Difference between Luminance image and 3D luminance mapping Hypothesis

We have two hypotheses about the effect of lighting on spaciousness. (Figure 4) The first hypothesis is about quantity of light. The brightness makes the spaciousness larger. The second hypothesis is about localization of light. When the luminance and its solid angle from the observer is the same, the localization to the far side of the room makes spaciousness larger.
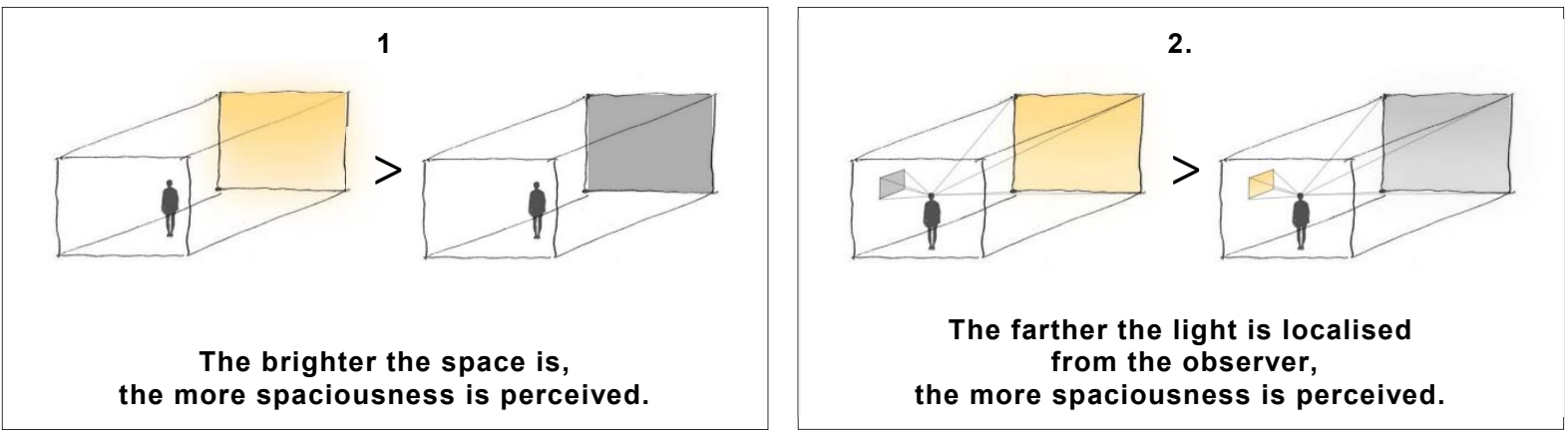

Figure 4 - Hypotheses

\section{Experiment}

\subsection{Outline of Experiment}

The aim of this experiment in a living room is to see the effect of quantity and localization of light on spaciousness to test if the hypotheses shown in chapter 1.2 are true. Comparing different lighting environments in the same living room, the subjects reported their perception 
of spaciousness and brightness. The subjects reported their opinion using the ME (magnitude estimation) method.

\subsection{Setting of Experiment Room}

The room was an existing living room, and we created 7 different lighting scenes with 4 downlights, 2 floor standing lights, one 6 meters cove light and 2 pendant lights as shown in Figure 5. These lights are controlled in 3 groups based on their location in the room. The first group was the downlights and the standing lights which were located far from the subjects. The second group was the pendant lights hung above the table just in front of the subjects. The third group was the cove light which runs 6 meters along the right-side wall. The lights could be controlled with switches and dimmers. The standard configuration was set with all 3 groups of lights on. So, there was minimal localization of light in the room. By turning on only one of the groups, we made different lighting scenes in which the localization of the light was different from the standard scene. A separated waiting space was prepared behind the experiment room and the lighting was dimmed down so that the vertical luminance to be 22 Ix which is the same as the standard scene.

Location: Existing living room in a house at Ibaraki, Japan

Dimensions: width $3640 \mathrm{~mm} \times$ depth $6370 \mathrm{~mm} \times$ height $2400 \mathrm{~mm}$

Note: All daylight is blocked with blackout curtains.
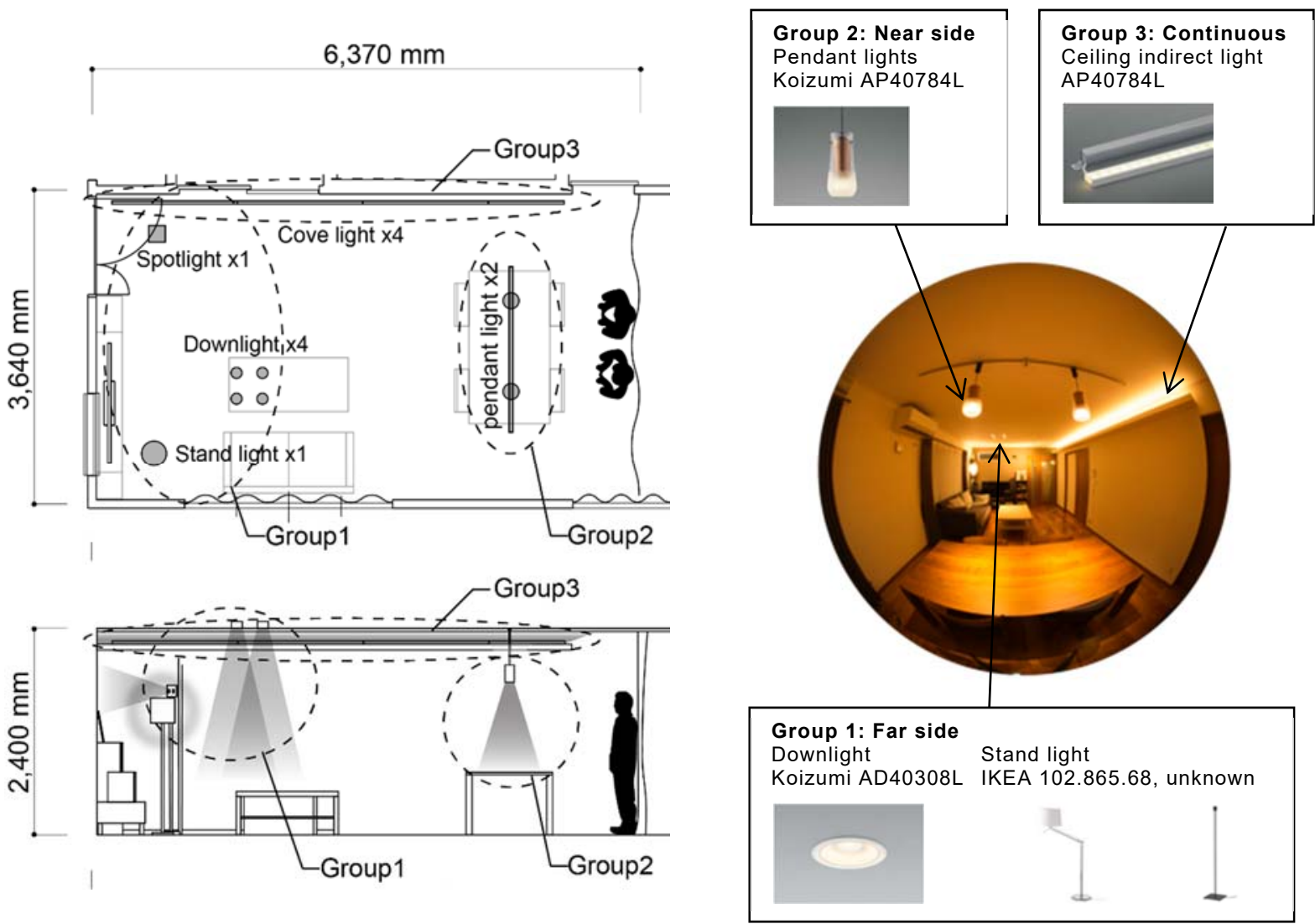

Figure 5 - Experiment Room Set-up and Lighting Fixtures 
Table 1 - Lighting Scenes

\begin{tabular}{|c|c|c|c|c|c|}
\hline $\begin{array}{l}\text { Scene } \\
\text { No. }\end{array}$ & Group & $\begin{array}{l}\text { Vertical } \\
\text { illuminance }\end{array}$ & Photo & $\begin{array}{c}\text { Captured } \\
\text { Luminance image }\end{array}$ & $\begin{array}{c}\text { Simulated } \\
\text { Luminance image }\end{array}$ \\
\hline $\begin{array}{l}0 \\
\times\end{array}$ & $\begin{array}{l}\text { Group } 1 \\
\text { Low } \\
\text { Group } 2 \\
\text { Low } \\
\text { Group } 3 \\
\text { Low }\end{array}$ & $22 \mathrm{Ix}$ & & & \\
\hline 1 & $\begin{array}{l}\text { Group } 1 \\
\text { Low }\end{array}$ & $7 \mathrm{Ix}$ & & & \\
\hline $\begin{array}{l}2 \\
\Delta\end{array}$ & $\begin{array}{c}\text { Group2 } \\
\text { Low }\end{array}$ & $7 \mathrm{Ix}$ & & & \\
\hline 3 & $\begin{array}{c}\text { Group } 3 \\
\text { Low }\end{array}$ & $7 \mathrm{Ix}$ & & & \\
\hline $\begin{array}{l}4 \\
0\end{array}$ & $\begin{array}{c}\text { Group } 1 \\
\text { High }\end{array}$ & $22 \mathrm{~lx}$ & & & \\
\hline $\begin{array}{c}5 \\
\Delta\end{array}$ & $\begin{array}{c}\text { Group } 2 \\
\text { High }\end{array}$ & $22 \mathrm{Ix}$ & & & \\
\hline $\begin{array}{l}6 \\
\square\end{array}$ & $\begin{array}{c}\text { Group } 3 \\
\text { High }\end{array}$ & $22 \mathrm{Ix}$ & & & \\
\hline
\end{tabular}

Symbols below the scene numbers are the same as the markers used in the result figures $8-10$ 


\subsection{Experiment procedure}

The quantification was done using the Magnitude Estimation (ME) method. Observing each scene, the subjects were asked to report their perception of spaciousness and brightness compared to the reference scene. (Assuming the reference "scene 0" as 100 spaciousness and 100 brightness.) The 10 subjects were separated into 5 pairs and the observation procedure was done pair by pair. The observation point was at one of the short sides which is close to the dining table as shown in figure 5 . The subjects were standing and facing the other short side of the room. They were only allowed to look around the space by moving their eyes but weren't allowed to turn their faces and bodies.

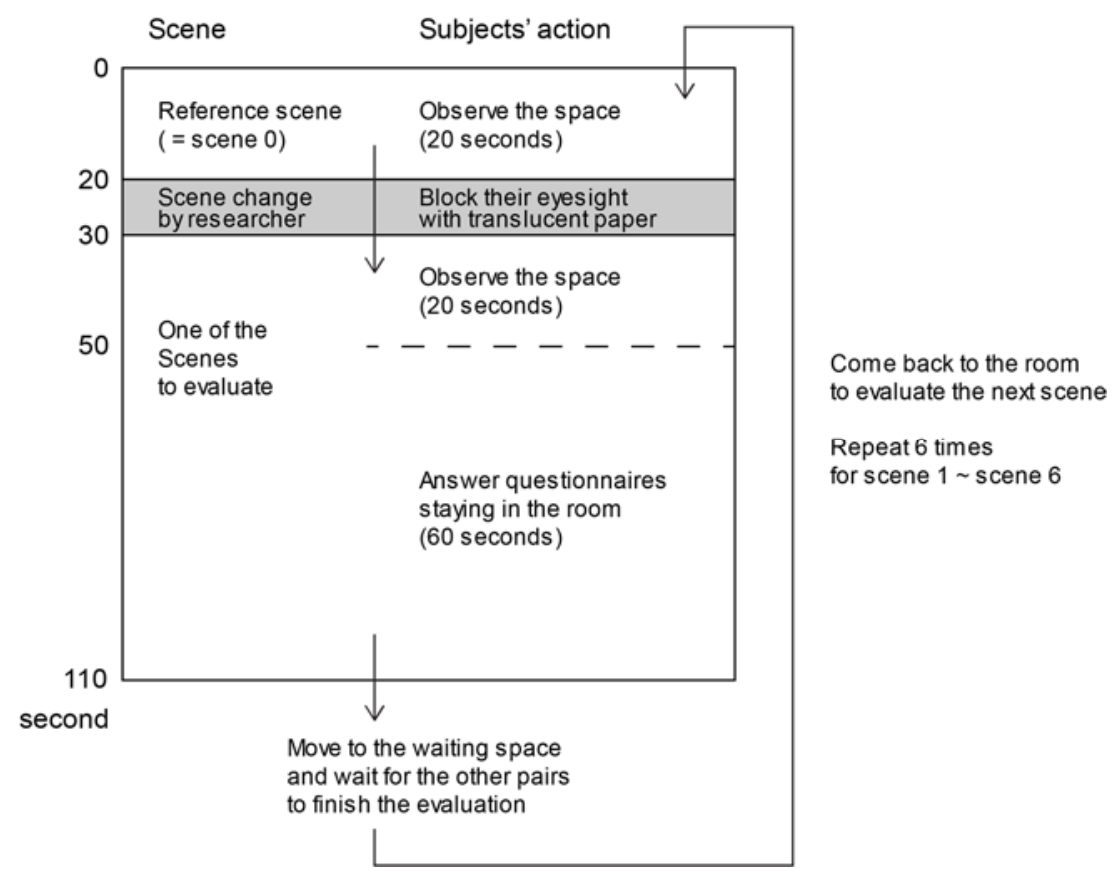

Figure 6 - Experiment Procedure

\subsection{D luminance mapping with Radiance}

In this research, it is necessary to capture luminance and its three-dimensional location at the same time. However, the system to capture the precise location of each pixel of luminance image by directly measuring the room has not been completed yet. As a result, to realize the 3D luminance mapping, we virtually re-built the space and the lighting scenes and have measured luminance and distance using Radiance RTRACE command.

Observation area: Hemisphere

Projection type: Equisolid projection

Resolution: Diameter 512 pixel circle $=205884$ pixels $(512 p x \times 512 p x \times(p i) / 4)$

Measured value:

- Luminance of surface toward subject $(\mathrm{cd} / \mathrm{m} 2)$

- Distance between subject and surface $(\mathrm{mm})$

- Unit vector directed from subject to surface $(x, y, z)$

We have created the virtual space by measuring the room and furniture dimensions with a laser measure and a tape measure. As it relates to the colour and reflectance of surfaces, we used a spectral reflection meter for measurement. We have also set up the lighting environment using IES data of fixtures. In addition, to minimise the difference between the virtual and the real space, we have adjusted the dimming level and light distribution to match the simulation result with the HDR luminance image created with the L-CEPT system using the Canon EOS 5D Mark3 camera and the SIGMA 8mm F3.5 EX DG equisolid circular fisheye lens. Example shown in Figure 7 below. 
The results of the simulation data and the measured data is shown in Chart 2. To minimise the difference, we checked the difference of vertical luminance between the real room and the virtual room. We adjusted the dimming level and the light distribution in the virtual room and made it closer to reality. After adjustment, the difference in vertical illuminance was smaller than $10 \%$ (between $-6 \%$ and $+6 \%$ ). The differences in arithmetic mean of pixel luminance were also smaller than $10 \%$ (between $+2 \%$ and $+10 \%$ ).
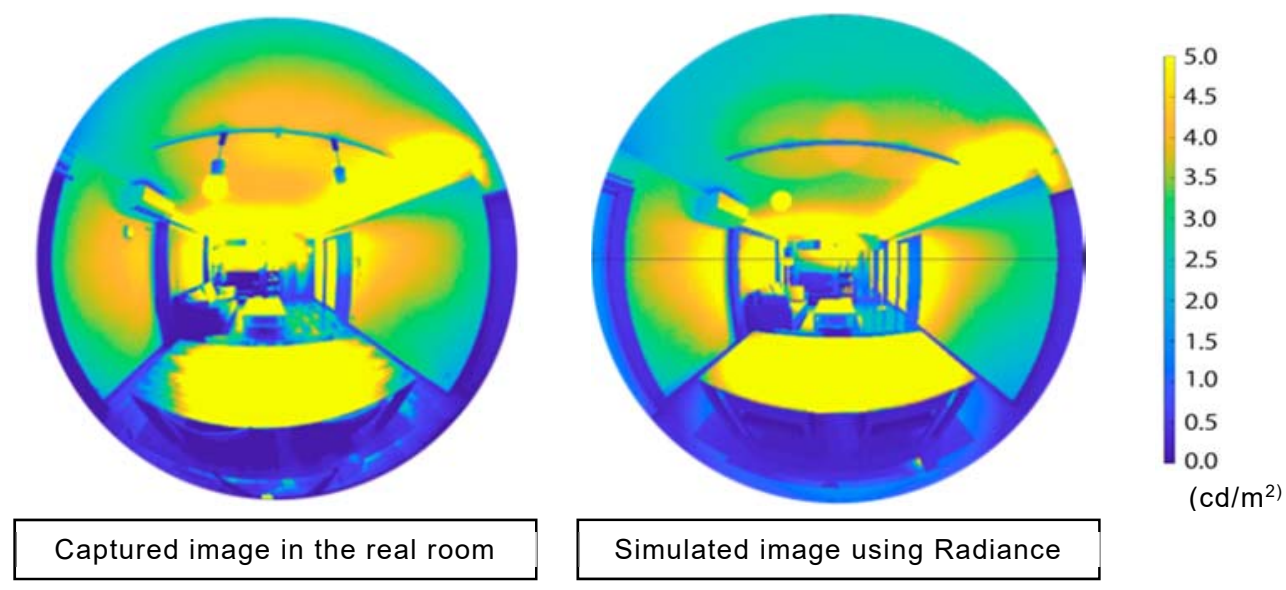

Figure 7 - Real and Virtual Luminance Image

Chart 2 - Comparison of measured data and simulated data

\begin{tabular}{|c|c|c|c|c|c|c|c|c|}
\hline & & Scene 0 & Scene 1 & Scene 2 & Scene 3 & Scene 4 & Scene 5 & Scene 6 \\
\hline \multirow{2}{*}{$\begin{array}{c}\text { Vertical luminance }(\mathrm{Ix}) \\
\text { at the face of subject }\end{array}$} & $\begin{array}{c}\text { Captured } \\
\text { in the real room }\end{array}$ & 22 & 7 & 7 & 7 & 22 & 22 & 22 \\
\cline { 2 - 9 } & $\begin{array}{c}\text { Simulated } \\
\text { with Radiance }\end{array}$ & 21,99 & 7,04 & 6,96 & 6,98 & 21,98 & 21,98 & 22,00 \\
\hline \multirow{2}{*}{$\begin{array}{c}\text { Average of luminance }\left(\mathrm{cd} / \mathrm{m}^{2}\right) \\
\text { of pixels }\end{array}$} & $\begin{array}{c}\text { Captured } \\
\text { in the real room }\end{array}$ & 5,17 & 1,36 & 1,64 & 1,79 & 4,64 & 4,94 & 5,71 \\
\cline { 2 - 9 } & $\begin{array}{c}\text { Simulated } \\
\text { with Radiance }\end{array}$ & 5,32 & 1,49 & 1,69 & 1,97 & 4,75 & 5,12 & 6,20 \\
\hline
\end{tabular}

\section{Result}

\subsection{Quantity of light and brightness}

Figure 8 shows the brightness of each scene reported by the 10 subjects. Comparing two scenes with the same luminaire group, brightness of scene in vertical illuminance $22 \mathrm{Ix}$ is always higher than that of scene in $7 \mathrm{Ix}$. (Scene $4>$ Scene 1 , Scene $5>$ Scene2, Scene $6>$ Scene 3 ). It means that the subjects could percept the difference in brightness in each pair.

\subsection{Quantity of light and spaciousness}

Figure 9 shows the spaciousness of each scene reported by the 10 subjects. To grab the outline, we compared all the scenes in $7 \mathrm{Ix}$ (scene 1, 2, 3) and all the scenes in $22 \mathrm{Ix}$ (scene 4, 5, 6), as shown in the right part of Figure 9. Spaciousness in $22 \mathrm{~lx}$ scenes was higher than that of 7 Ix. With paired two-sample t-test, the $p$ value was $0,0005(<0,05)$. This means that the hypothesis 1 is correct (The brighter the space is, the more spaciousness is perceived). We also have compared two scenes with the same luminaire group. Spaciousness in scene 4 was higher than that of scene 1 -the $p$ value was $0,022(<0,05)$. Although the average of spaciousness in scene 5 was higher than the average in scene 2 -the $p$ value was 0,32 , so the 
difference was not clear and further study is required. Spaciousness in scene 6 was higher than that of scene 3 -the $p$ value was $0,017(<0,05)$.

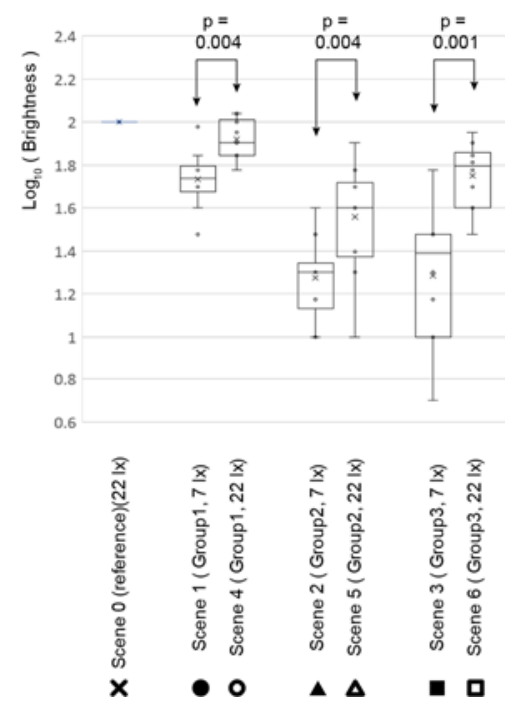

Figure 8 - Brightness and Vertical Illuminance
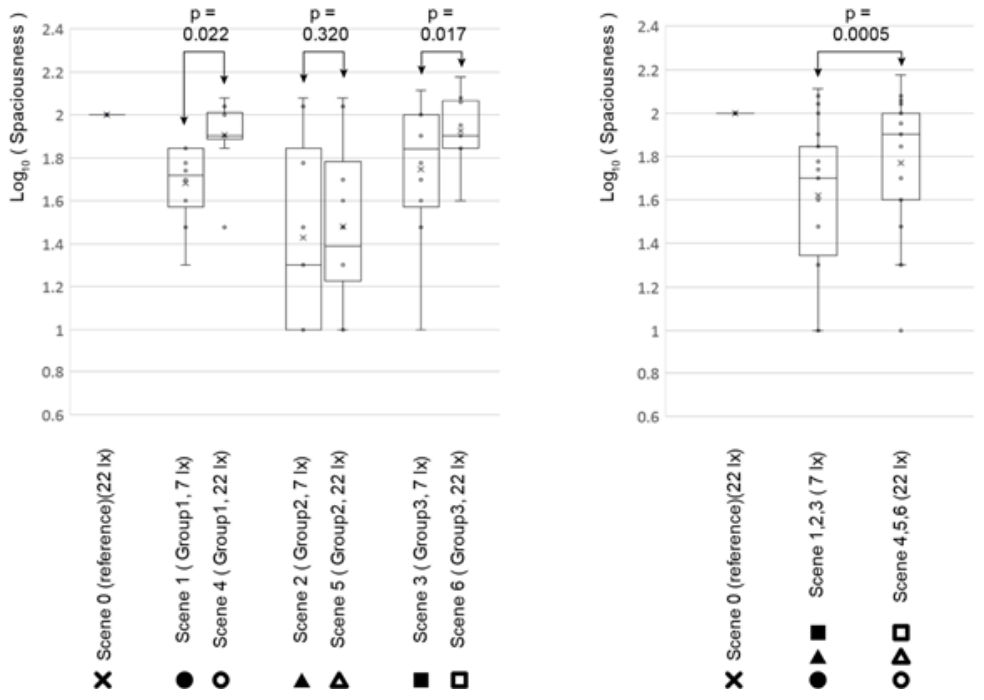

Figure 9 - Spaciousness and Vertical Illuminance

\subsection{Localisation of light and spaciousness}

To take into consideration the localization of light, we used the distance between the surface and the observer as a variable. Two other variables were the luminance of each pixel and the angle of direction from the view axis $(\theta)$. We multiplied $\cos (\theta)$ to take the direction into consideration, as the effect on the perception from the pixels close to the centre of view should be greater than the pixels at the perimeter.

The scattering plot in the left of Figure 10 shows the relation between spaciousness, luminance and direction, but without distance. As the arithmetic mean of each pixel of (Luminance $\times \cos (\theta)$ ) is proportional to vertical illuminance, the $x$-values in scene 1,2, 3 are almost identical, as is the case for scene 4, 5, 6. Without considering distance, coefficient determination value was only 0,1594 .

For the scattering plot in the middle of Figure 10 , we have multiplied distance $(\mathrm{mm})$ to (Luminance $\times \cos (\theta)$ ) before calculating the arithmetic mean. With this multiplication of distance, the farther the light is localised from the observer, the greater the $x$-value becomes. The coefficient determination value increased to 0,6178. Thus, hypothesis 2 (The farther light is localized from the observer, the more spaciousness is perceived) is also correct. However, further study is required as the lighting type was also different between the groups.

\subsection{Elimination of the luminous surface from the calculation}

One of the reasons why the spaciousness in case 2 and case 5 is lower than the others, could be due to the direct visibility of the luminous surface of the lighting fixture. In perception of surface, a luminous surface can act differently from other surfaces which just reflect light (Katz, 1935). The scattering plot in the right of Figure 10 is the result after eliminating the pixels of the luminous surface from the arithmetic mean (The spotlight and the downlights in group 1 , the pendant lights in group 2). The coefficient determination value went up to 0,8145 . Thus, we can say that eliminating the luminous surface of the light source makes the description model better. 

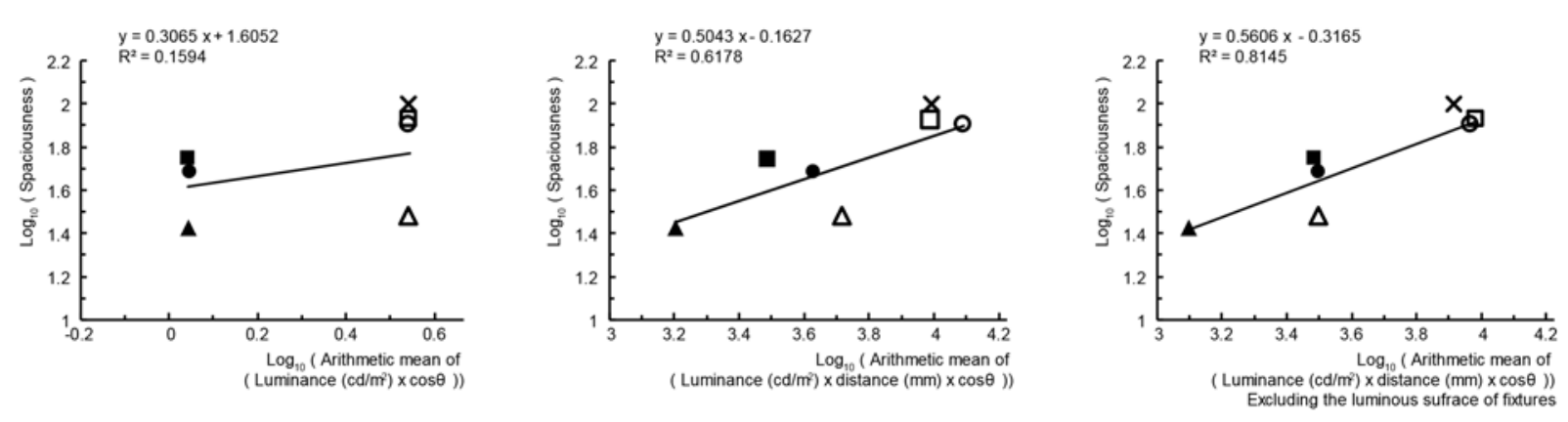

X Scene 0 (reference) $(22 \mathrm{~lx})$

(Not included in the regression analysis)

Scene 1 ( Group1, 7 |x)

Scene 4 ( Group1, 22 Ix)

Scene 2 ( Group2, 7 |x)

Scene 5 ( Group2, 22 Ix)

Scene 3 ( Group3, 7 |x)

Scene 6 ( Group3, 22 Ix)

\section{Figure 10 - Spaciousness, Luminance, Distance and Direction}

\section{Conclusion}

In this report, even though it is clear that both quantity and localization of light affect the perception of spaciousness, the result also showed that light distributed around the room makes spaciousness even larger. Further experiment is required using a specially prepared space for this research where lighting fixtures and scenes can be controlled more flexibly and precisely. Furthermore, the research should include different spaces (in terms of scale and use) and the effect from openings with natural light.

\section{References}

AYA, K., YOSHIZAWA, N., YAMAGUCHI, H., HARA, N., KATO, M., MIKI, Y., 2015. The relationship between the brightness of overall space and the brightness in the specific visual field in the non-uniform illuminated space, Proceedings of 28th CIE Session 2015. CIE, Manchester, UK, pp. 1466-1470.

BOYCE, P., 2014. Editorial: Light distribution - a missing variable. Light. Res. Technol. 46, 617-617. https://doi.org/10.1177/1477153514556940

CHRISTOPH, V. C., HEIKO, H., DANIEL, O., 2018a. Bright paint makes interior-space surfaces appear farther away. PLOS ONE September 5, 2018, https://doi.org/10.1371/journal.pone.0201976

CHRISTOPH, V. C., HEIKO, H., DANIEL, O., 2018b Measuring perceived ceiling height in a visual comparison, task. The Quarterly Journal of Experimental Psychology 70(3): 516532. https://doi.org/10.1080/17470218.2015.1136658

CUTTLE, C., 2004. Brightness, lightness, and providing "a preconceived appearance to the interior." Light. Res. Technol. 36, 201-214. https://doi.org/10.1191/1365782804li115oa

DUFF, J., KELLY, K., CUTTLE, C., 2015, Spatial brightness, horizontal illuminance and mean room surface exitance in a lighting booth. Lighting Research \& Technology Volume: 49 issue: 1, page(s): 5-15 https://doi.org/10.1177/1477153515597733

FAWZI, A. A. 2017. The Impact of Design Elements on the Perception of Spaciousness in Interior Design. International Design Journal, Volume 7, Issue 2, 177-187, http://dx.doi.org/10.12816/0046564

INUI, M., MIYATA, T., WATANABE, K., 1972a. Evaluation of spaciousness (1). Transactions of the Architectural Institute of Japan 192(0), 49-55, 88, 1972

https://doi.org/10.3130/aijsaxx.192.0_49 
INUI, M., MIYATA, T., WATANABE, K., 1972b. Evaluation of spaciousness (2). Transactions of the Architectural Institute of Japan 193(0), 51-57,89, 1972 https://doi.org/10.3130/aijsaxx.193.0_51

INUI, M., MIYATA, T., WATANABE, K., 1972c. Evaluation of spaciousness (3). Transactions of the Architectural Institute of Japan 194(0), 39-44,96, 1972 https://doi.org/10.3130/aijsaxx.194.0_39

Imamoglu, V., 1986, Assessing the spaciousness of interiors. METU Journal of the Faculty of Architecture 7(127-142).

KATO, M., SEKIGUCHI, K., 2005. "Impression of Brightness of a Space" Judged by Information from the Entire Space. J. Light Vis. Environ. 29, 123-134. https://doi.org/10.2150/jlve.29.123

KATZ, D., 1935, The world of Colour, London: Kegan Paul Trench, Trubner \& Co.,

KOMIYAMA, A., HATSUMI, M., 1996, Cognitive Structure of Ceiling Height of Interior Space. Journal of Architecture and Planning (Transactions of AlJ) Volume 61 Issue 490 Pages 111-118, https://doi.org/10.3130/aija.61.111_3

KOBAYASHI, S., NAKAMURA, Y., INUI, M., 1998. Impressions of Overall Brightness in a Non-Uniformly Illuminated Space. J. Light Vis. Environ. 22, 1_34-1_41. https://doi.org/10.2150/jlve.22.1_34

SULLIVAN, J., DONN, M.,2018, MEASURING THE EFFECT OF LIGHT DISTRIBUTION ON SPATIAL BRIGHTNESS, Conference: CIE 2017 Midterm Meetings and Conference on Smarter Lighting for Better Life http://dx.doi.org/10.25039/x44.2017.OP49

TILLER, D.K., VEITCH, J.A., 1995. Perceived room brightness: Pilot study on the effect of luminance distribution. Light. Res. Technol. 27, 93-101. https://doi.org/10.1177/14771535950270020401

UCHIDA, S. 1979. An Experimental Study on the Sense of Visually-closed Spaces Part-II. Transactions of the Architectural Institute of Japan 1979 Volume 285 Pages 117-125 https://doi.org/10.3130/aijsaxx.285.0_117

WALDRAM, J.M., 1969. IES Diamond Jubilee Lecture: Light and the community Part 2 The growth of lighting. Light. Res. Technol. 1, 78-85. https://doi.org/10.1177/14771535690010020601 